\title{
Evolution of flowers and inflorescences
}

\author{
Enrico S. Coen and Jacqueline M. Nugent \\ John Innes Centre, Colney, Norwich NR4 7UH, UK \\ *Author for correspondence
}

\section{SUMMARY}

Plant development depends on the activity of meristems which continually reiterate a common plan. Permutations around this plan can give rise to a wide range of morphologies. To understand the mechanisms underlying this variation, the effects of parallel mutations in key developmental genes are being studied in different species. In Antirrhinum, three of these key genes are: (1) floricaula (flo) a gene required for the production of flowers (2) centroradialis (cen), a gene controlling flower position (3) cycloidea (cyc), a gene controlling flower symmetry. Several plant species, exhibiting a range of inflorescence types and floral symmetries are being analysed in detail. Comparative genetic and molecular analysis shows that inflorescence architecture depends on two underlying parameters: a basic inflorescence branching pattern and the positioning of flowers. The flo and cen genes play a key role in the positioning of flowers, and variation in the site and timing of expression of these genes, may account for many of the different inflorescence types. The evolution of inflorescence structure may also have influenced the evolution of floral asymmetry, as illustrated by the cen mutation which changes both inflorescence type and the symmetry of some flowers. Conflicting theories about the origins of irregular flowers and how they have coevolved with inflorescence architecture can be directly assessed by examining the role of $c y c$ - and $c e n$-like genes in species displaying various floral symmetries and inflorescence types.

Key words: Antirrhinum, Arabidopsis, symmetry

\section{INTRODUCTION}

The development of plants depends on the activity of their meristems, groups of dividing cells located at the growing points. These meristems can continue to add new structures to the plant throughout its life history, giving it the potential for indeterminate growth. They achieve this by generating two types of structure on their periphery: primordia which will grow to form organs such as leaves, petals and stamens; and secondary meristems, which will form side branches or flowers. In most cases each primordium has a secondary meristem located in its axil (the angle between the base of the primordium and the main stem). By changing a few of the key features of meristems, it is possible to account for much of the evolutionary variation in plant form. Here we present a comparative molecular genetic approach to understanding how such changes may account for variation in inflorescence architecture and floral symmetry.

Plants offer several advantages for comparative analysis. Parallel genetic studies have been carried out in several species, allowing comparisons of mutations in key genes. Several species can be transformed, permitting the transfer of genes between species to assess how the role of these genes may have changed during evolution. The indeterminate growth pattern of plants gives them the potential to produce many different morphologies through limited modifications in the properties of their meristems. Thus, analysing key genes controlling meristem behaviour may give important insights into how diverse plant forms have evolved.

\section{TYPES OF INFLORESCENCE}

Most plants have flowers clustered together in a region termed the inflorescence. Inflorescences have been classified according to several criteria (Weberling, 1989). These include whether the inflorescence is: (1) determinate, where the main axis of growth ends in a flower (Fig. 1a-d), or indeterminate, in which there is no terminal flower (Fig. 1e-i); (2) racemose, having a branching pattern with a single main axis of growth (Fig. le-h), or cymose, having a branching pattern which lacks a main axis (Fig. 1c,d); (3) simple, in which no secondary branches are produced (Fig. la,b,e,h,i), or compound, which produce secondary and sometimes higher order branches (Fig. lc,d,f,g); (4) bracteose which have leaf-like organs (bracts) subtending flowers, or bractless.

Most of these criteria depend on two underlying parameters, a basic inflorescence branching pattern and the positions of flowers. Since, by definition, an inflorescence must comprise both flowers and branch points, these two parameters normally cannot be uncoupled and their individual contributions to inflorescence architecture assessed separately. However, by using a molecular genetic approach to analyse inflorescence mutants, we can begin to separate the various parameters and assess their role in the evolution of inflorescence types. 


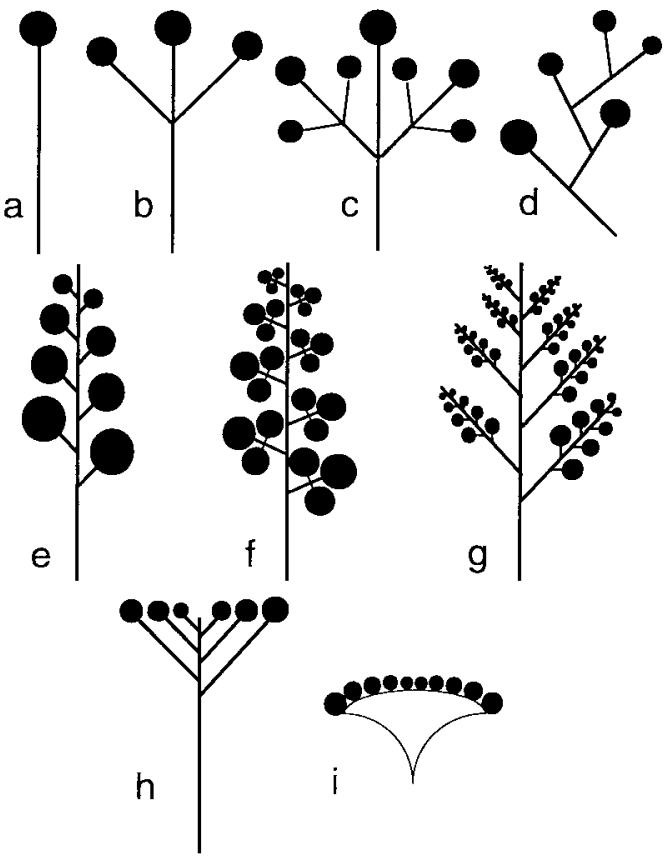

Fig. 1. Diagrammatic illustration of various inflorescence types. (a) Solitary terminal flower; (b) simple dichasium; (c) compound dichasium; (d) cyme; (e) raceme; (f) thyrse; (g) compound raceme; (h) corymb; (i) capitulum. Flowers are indicated by solid circles. Bracts are not shown.

\section{DEFINING THE PRIMARY INFLORESCENCE BRANCHING PATTERN}

The first gene affecting inflorescence development to be studied in detail was floricaula (fo) in Antirrhinum majus (Carpenter and Coen, 1990; Coen et al., 1990). Vegetative growth in Antirrhinum is characterised by the production of two opposite leaves at each node of the main stem. After the plant has produced several vegetative nodes, it switches to the reproductive phase, characterised by the production of single flowers in the axils of bracts separated by short internodes on a hairy stem (Fig. 2). This type of inflorescence, comprising a series of axillary flowers arranged along a single main axis, is termed a raceme (Fig. 1e). In flo mutants, flowers are replaced by shoots (Fig. 2) that have some characteristics of the reproductive phase of growth (bracts, short internodes, hairy stem). These secondary shoots can themselves produce further shoots, termed tertiary shoots, in the axils of their bracts. The overall result is that the raceme has been replaced by a flo-independent branching structure that is never terminated by the production of flowers.

One interpretation of the flo mutant phenotype is that it reflects an alteration in the identity of meristems. In Antirrhinum there are three types of meristem that are distinguished by the types and arrangements of organ primordia and the secondary meristems they produce. The vegetative meristem produces leaf primordia with secondary vegetative meristems in their axils. The inflorescence meristem normally produces bract primordia with floral meristems in their axils. Floral meristems produce floral organ primordia but unlike the other meristem types, do not give rise to secondary meristems. A further distinguishing feature of floral meristems is that after they have produced a defined number of primordia they cease to be active. Thus floral meristems are determinate and provide endpoints to the growth of an axis whereas vegetative and inflorescence meristems are indeterminate.

In the flo mutant, the main inflorescence meristem produces secondary inflorescence meristems, rather than floral meristems, in the axils of its bract primordia. These secondary meristems can in turn produce further meristems on their periphery and this process can continue indefinitely leading to even higher order meristems. The flo gene is therefore required to establish floral meristem identity and in its absence, indeterminate branching ensues. This early requirement for flo correlates with its expression pattern, as determined by in situ hybridisation (Coen et al., 1990). Transcripts of flo are detected in initiating floral meristems and their subtending bract primordia but are not observed in either the main infloresence meristem or in vegetative meristems (Fig. 3). Localisation of flo expression within particular meristems is therefore an important determinant of which meristems will form flowers. At later stages of development, flo is expressed transiently in all floral organ primordia except stamens.

One way to alter inflorescence architecture might be to change the site or timing of flo expression. This can be illustrated by using wild-type Antirrhinum as a starting point and predicting the phenotype produced when flo expression is altered in several ways. A slight delay in flo activation, such that it does not come on immediately in secondary meristems but after some tertiary branching is initiated, would give a cluster of flowers instead of single axillary flowers. This could give rise to a compound inflorescence where each secondary branch comprises a small cyme (thyrse, Fig. 1f). Another possiblity would be changing flo expression such that it only came on in tertiary rather than secondary meristems. This would result in each flower being replaced by an indeterminate axillary raceme, giving rise to a compound raceme (Fig. 1g).

\section{DETERMINATE VERSUS INDETERMINATE INFLORESCENCES}

Whereas a delay of flo expression might be expected to produce a more highly branched inflorescence, ectopic expression of flo could be involved in producing more compact or determinate inflorescences. One way to convert an indeterminate inflorescence to a determinate condition would be to replace the main inflorescence apex by a flower. This is illustrated by centroradialis (cen) mutants of Antirrhinum (Stubbe, 1966) which produce a short raceme, terminated by a single flower (Fig. 4, note that the shape of the terminal flower is distinct, see below). Presumably, in wild-type plants this gene prevents expression of flo and other genes needed for flower development in the inflorescence apex.

It has been suggested that the indeterminate inflorescence is a derived condition, which required a mechanism for repressing terminal flowers to have evolved (Stebbins, 1974). Furthermore, because species with indeterminate inflorescences are present in a wide range of taxa, interspersed with species having a determinate condition, it is believed that a genetic mechanism for repressing terminal flowers must have arisen 
independently many times. However, it is equally plausible that a mechanism for repressing terminal flowers was derived at an early stage during the evolution of flowering plants and that in many lineages determinate inflorescences have been secondarily derived through loss of this mechanism. Is it possible to distinguish between these two scenarios? According to the multiple gain hypothesis, the mechanism for establishing indeterminacy might be expected to be different in distantly related species. However, according to the multiple loss theory, many species could share the same underyling mechanism for establishing indeterminacy. One way to distinguish between these possibilities is to establish whether the genes controlling indeterminacy in other species are homologous to cen. For example, the terminal flower ( $t f l$ ) mutant of Arabidopsis thaliana has a comparable phenotype to cen. If $t f$ and cen encode distinct proteins, it would suggest that Arabidopsis and Antirrhinum might have acquired indeterminacy through different routes. If the cen and $t f$ genes are homologous, it would imply that the indeterminate condition of Antirrhinum and Arabidopsis may not have been independently acquired but was present in their common ancestor.

\section{RACEMOSE VERSUS CYMOSE BRANCHING}

The previous examples illustrate how some inflorescence architectures might arise through changing the expression pattern of floral meristem identity genes such as flo. If this were the only way of altering inflorescence type, flo-like mutants in all species would reveal essentially the same primary branching pattern. This can be directly assessed in several cases.

The most intensively studied flo homologue in another species is the lfy gene of Arabidopsis (Weigel et al., 1992; Schultz and Haughn, 1991). Vegetative growth of wild-type Arabidopsis produces a rosette of leaves separated by short internodes. On entering the reproductive phase, the plant bolts to generate an elongated main stem, the lower part of which has several small leaves (cauline leaves) and the upper part bears flowers arranged as a raceme. Secondary inflorescences are initiated within the axils of the cauline leaves (Fig. 2). In lfy mutants, the plant bolts as normal but flowers are replaced by secondary shoots subtended by cauline leaves. In older plants, the secondary shoots produced at the top of the bolt, display some floral characteristics, showing that some features of flower development can be restored, even in the absence of lfy activity.

The basic branching pattern underlying the Arabidopsis inflorescence, as revealed by the lfy mutant, is very similar to that of Antirrhinum (Fig. 2). In both cases there is a main axis of growth with secondary shoots arising in axillary positions. This similarity may reflect the fact that wild-type Arabidopsis and Antirrhinum share the same overall inflorescence architecture, the raceme. A more revealing comparison might be to analyse the flo-independent branching pattern in species with markedly different inflorescence types.

The tomato (Lycopersicon esculentum) inflorescence has a cymose branching pattern. After vegetative growth, the main apical meristem becomes a terminal floral meristem associated with an adjacent secondary meristem. The secondary meristem terminates with the production of a flower and a tertiary meristem. By repeating this pattern of growth, tertiary and higher order flowers are successively produced to form a cymose inflorescence. Although initially in an apical position, the whole inflorescence eventually becomes displaced by an axillary leafy shoot which continues the main growth of the plant (Fig. 2). After producing about three leaves the axillary shoot repeats the growth pattern of the primary shoot. This growth pattern, termed sympodial growth, could be a consequence of expressing $f l o$-like genes in the apical meristem and in secondary, tertiary and higher order meristems derived from it. By committing the apical meristem to producing flowers, the continued growth of the plant would have to occur from an axillary meristem. According to this view, a flo-like mutant in tomato should have an indeterminate leafy shoot with a single primary axis of growth, similar to that seen for the flo and lfy mutants of Antirrhinum and Arabidopsis. Alternatively, sympodial growth may not be a consequence of flower production but may reflect the $f l o$-independent primary branching pattern of tomato. In this case, flo-like mutants in tomato should retain sympodial growth.

The falsiflora ( $\mathrm{fa}$ ) mutant of tomato lacks a flowering inflorescence and produces a highly branched system of shoots instead (Stubbe, 1963, Fig. 2). The mutant still exhibits sympodial growth, showing that this growth pattern is independent of flower production. Preliminary genetic and molecular results indicate that $f a$ may be the tomato homologue of $f l o$. However, the $f a$ mutation reveals a primary branching pattern that is quite distinct from that revealed by flo or $l f y$. Unlike $f l o$ and $l f y$, the $f a$ branching system that replaces the inflorescence, lacks a main axis of growth, even though it proliferates extensively. This suggests that the wild-type tomato inflorescence can be distinguished from that of Antirrhinum or Arabidopsis by two features: a cymose primary branching pattern which is flo-independent and the production of terminal flowers which is flo-dependent. Both of these features can be seen as reflecting early meristem behaviour.

\section{BRACTEOSE VERSUS BRACTLESS INFLORESCENCE}

In addition to overall architecture, another feature that distinguishes inflorescences is the presence or absence of bracts subtending the flowers. Antirrhinum has flowers subtended by bracts (bracteose infloresence) whereas Arabidopsis flowers are bractless (Fig. 2). The absence of bracts is a general feature of the family Cruciferae, to which Arabidopsis belongs and is thought to be a derived condition. In lfy mutants, shoots or abnormal flowers often with subtending bracts, are produced where bractless flowers would normally arise (Schultz and Haughn, 1991; Weigel et al., 1992). This demonstrates that the bractless condition is to a large extent lfy-dependent. The analysis of flo and lfy expression indicates how the bractless condition may have evolved.

In Antirrhinum, flo is expressed in floral meristems and their subtending bract primordia. In Arabidopsis, lfy is only expressed in floral meristems. However, when bract primordia are allowed to form in Arabidopsis, as in lfy mutants, they accumulate lfy RNA, giving an expression pattern similar to that of wild-type Antirrhinum (Fig. 3).

One interpretation of these results is that originally lfy was 


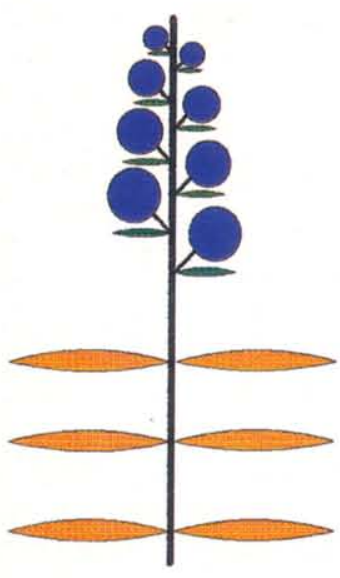

Antirrhinum

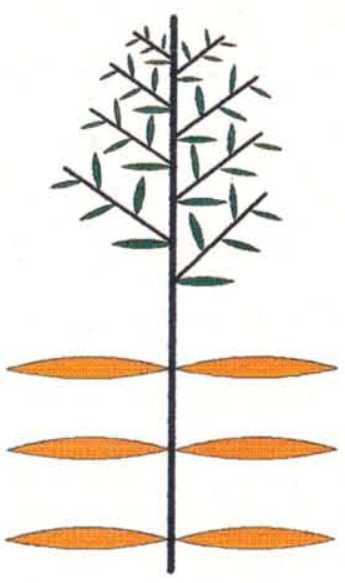

floricaula

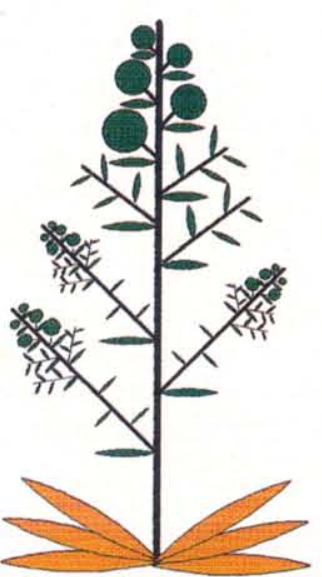

Jeafy

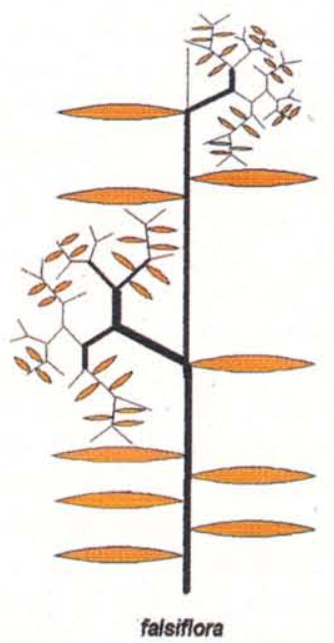

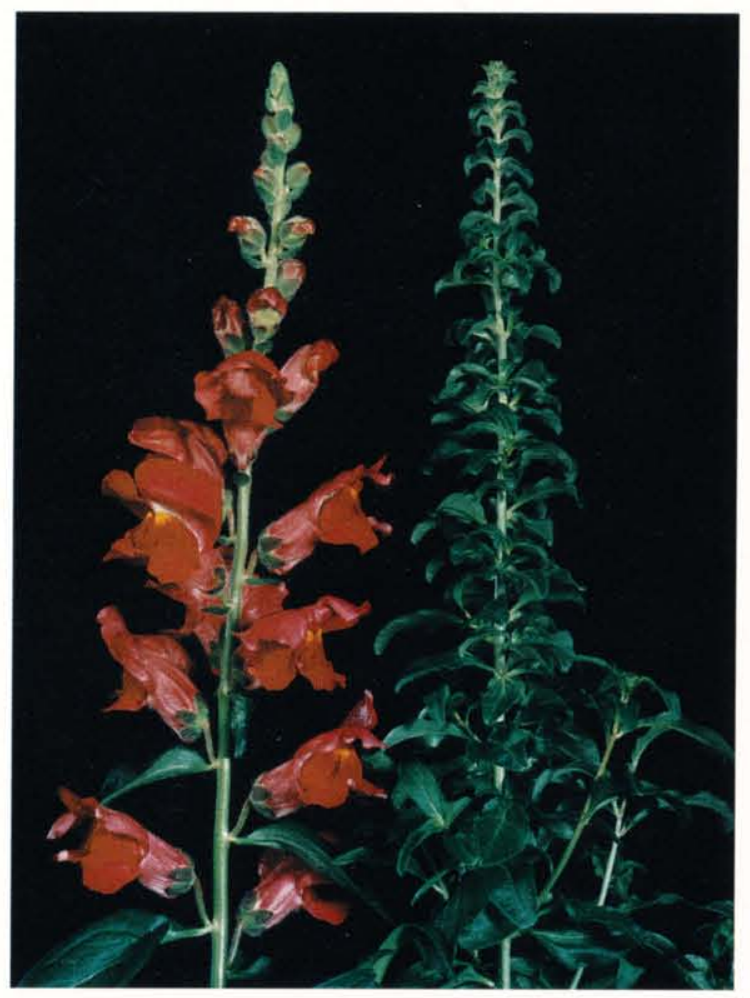
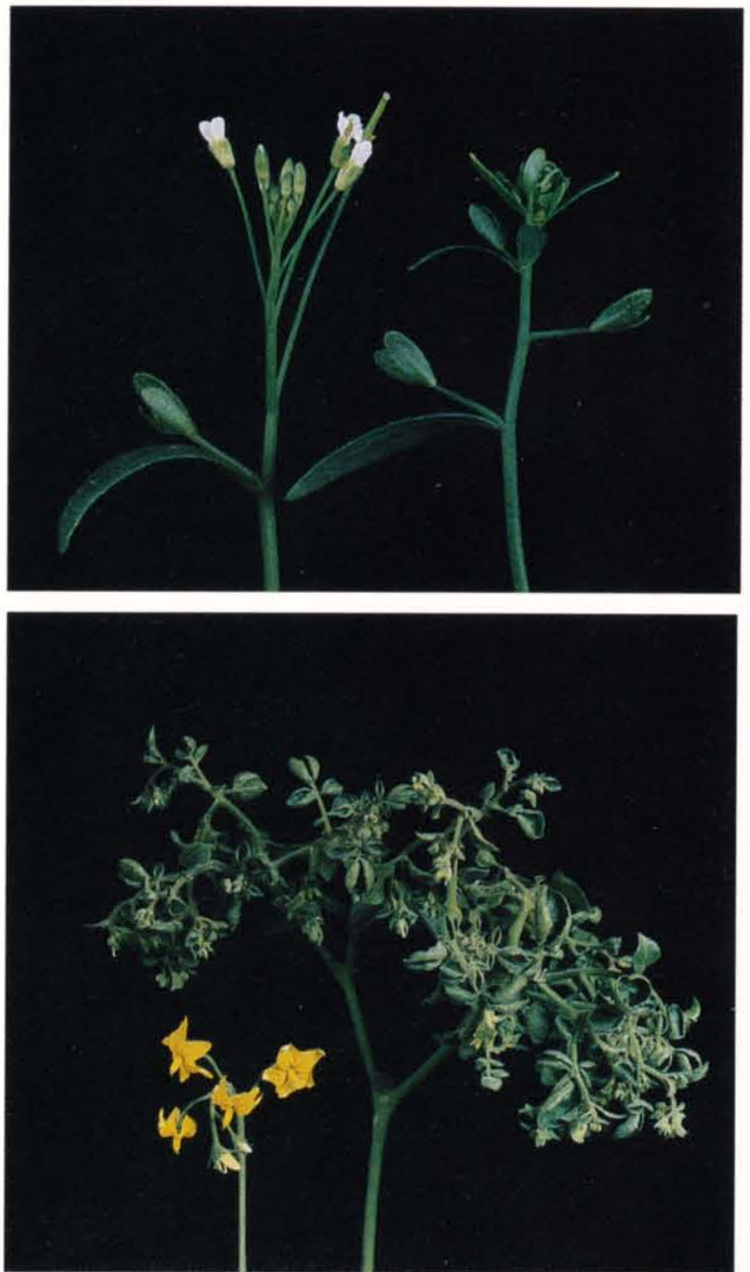

Fig. 2 
flo/ly expression

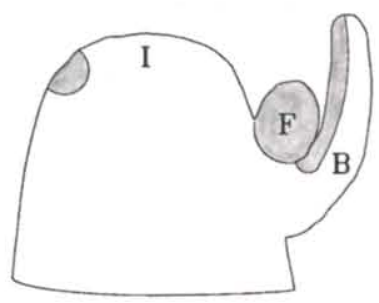

wild type

Antirrhinum

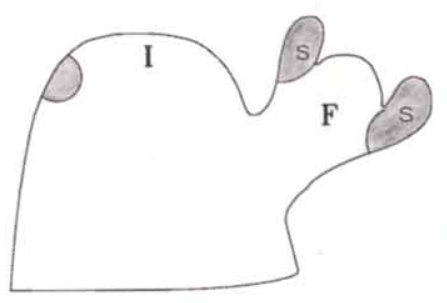

wild type

Arabidopsis

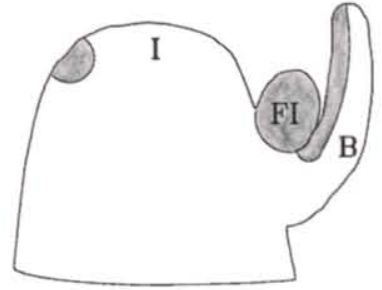

leafy
Fig. 3. Expression pattern of flo in wild-type Antirrhinum and lfy in wildtype and mutant Arabidopsis.

Abbreviations: I, inflorescence meristem; F, floral meristem; B, bract primordium; s, sepal primordium; FI, meristem with both floral and inflorescence character. expressed in flower meristems and bract primordia, as in Antirrhinum. Subsequently, in a common ancestor of the Cruciferae, Ify acquired the role of incorporating cells that would normally go on to form the bract, into the floral meristem. The bracts are therefore suppressed, not by inhibiting the activity of a bract-forming region, but by incorporating the cells from such a region into the flower. The advantage of recruiting all cells to form a flower without the attending bract might be to accelerate flower development. This is illustrated in lfy mutants, where the development of floral meristems subtended by bracts is retarded relative to wildtype, presumably because they start off with fewer cells (Fig. 3).

In some members of the Cruciferae, the role of lfy in cell recruitment may be partly separated from its role in flower production. For example, in Alyssum, the secondary inflorescences that are produced just below the main raceme, are not subtended by cauline leaves (Fig. 5 ). One possible explanation is that

Fig. 2. Diagrammatic illustrations and photographs comparing wild-type and flo mutant of Antirrhinum (top panel), wild-type and lfy mutant of

Arabidopsis (middle panel) and wildtype and fa mutant of tomato (bottom panel). In all cases, wild type is shown on the left. In the diagrammatic illustrations, leaves are shown in brown, bracts or cauline leaves in green, flowers as blue circles and abnormal "flowers" as green circles. In the photographs, only the upper part of the plant is shown for Antirrhinum and Arabidopsis and only single

inflorescences are shown for tomato.

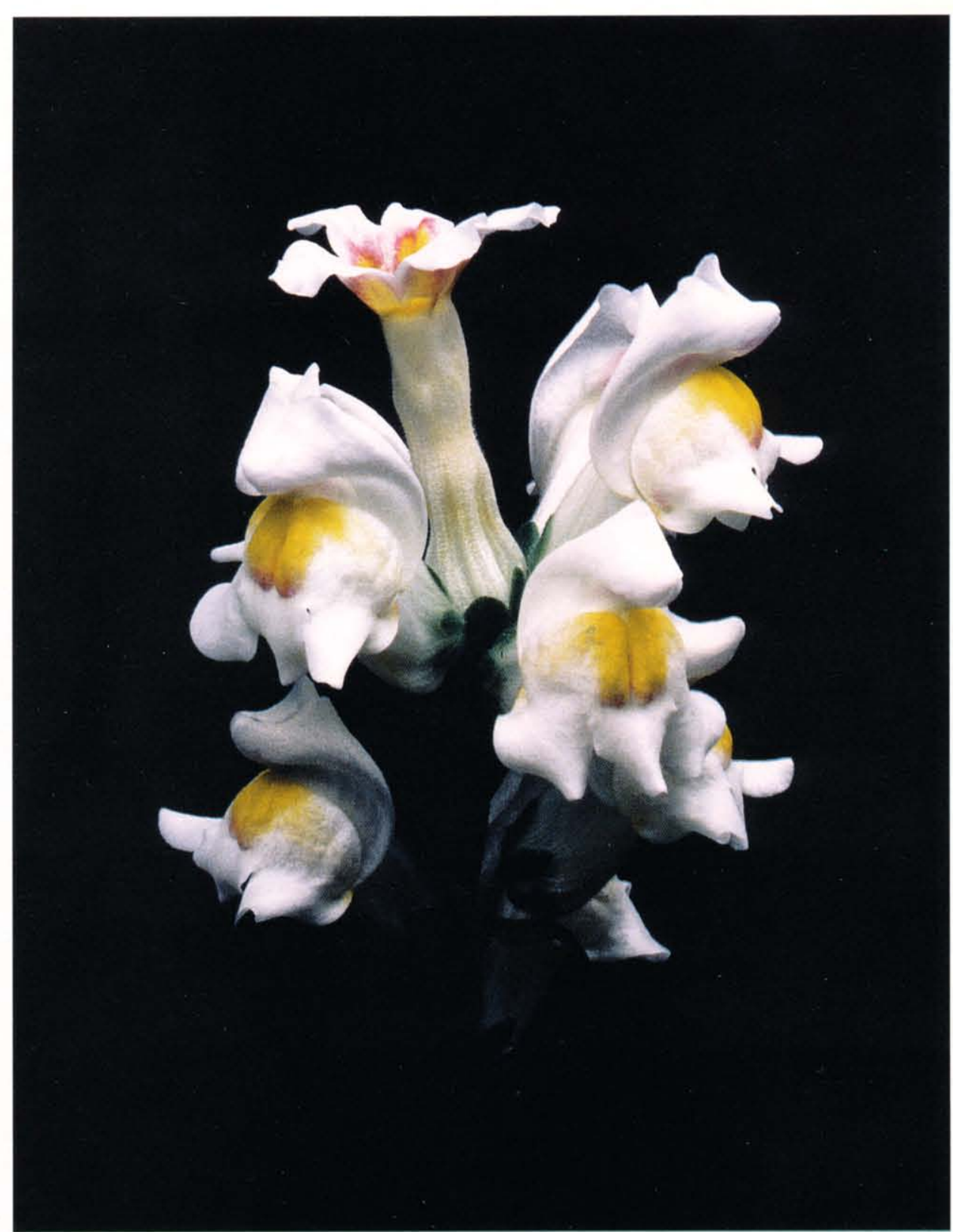

Fig. 4. Photograph of the inflorescence of an Antirrhinum cen mutant shown from the side. Note the symmetrical terminal flower. 
in these cases, lfy is acting to incorporate cells, that would normally go on to form the cauline leaf, into the meristem of the secondary inflorescence. Within the main raceme of Alyssum, the lfy gene acts as it does in Arabidopsis, recruiting cells into the secondary meristem and switching its identity to that of a floral meristem.

The emergence of the bractless condition may reflect an alteration in the lfy itself and/or alterations in target genes acting downstream of lfy. One way to test this would be to transform lfy mutants with flo and observe its expression pattern and phenotypic consequences. Preliminary results indicate that flo does not complement the lfy mutant, suggesting that some functionally important differences exist between these genes (R. Elliott, J. Nugent, R. Carpenter and E. Coen, unpublished results). Further experiments, such as swapping domains between lfy and flo, may shed light on where the key differences reside.

\section{EVOLUTION OF FLORAL SYMMETRY}

Flowers are classified as being either irregular, having only one plane of mirror symmetry or regular, having more than one plane of symmetry. The most intensive genetic analysis of floral symmetry has been carried out in Antirrhinum, which has irregular flowers that are markedly asymmetrical along their dorsoventral axis. Wild-type Antirrhinum flowers consist of five petals that are united for part of their length to form a tube ending with five lobes. The petal lobes are of three types: two large dorsal (upper) petals, two side petals and a ventral (lowest) petal. The flower is also irregular with respect to the stamens. Five stamens are initiated, alternate with the petals and are also of three types: the dorsal stamen is aborted and the two side stamens are shorter than the two ventral stamens. Mutations in cycloidea (cyc) give regular flowers with five-fold symmetry in certain genetic backgrounds (Fig. 6). All five petals and stamens resemble the ventral petal and stamens of the wild-type. It has been proposed that the irregular phenotype of wild-type flowers is dependent on $c y c$ activity establishing an axis of dorsoventral asymmetry. The activity of $c y c$ is predicted to be greatest in the dorsal regions of the flower meristem and to decline towards the more ventral regions. This would account for the ventralised phenotype of $c y c$ mutants (Carpenter and Coen, 1990).

Early flowering plants are thought to have had regular flowers and irregularity is considered to be a derived condition. The analysis of genes like cyc allows us to address several important questions about the genetic basis of this evolutionary change: what role might $c y c$ have played in the ancestral species with regular flowers and how was $c y c$ subsequently recruited to establish dorsoventral asymmetry? How many times has irregularity evolved and has it always involved $c y c$ ? Before considering these questions it is important first to consider the current view of how irregularity has evolved, largely based on comparative morphology.

Irregularity is thought to have evolved independently many times, perhaps arising on as many as 25 separate occasions (Stebbins, 1974). The alternative to this multiple gain hypothesis, is that irregularity arose only a limited number of times and was subsequently lost several times in independent lineages. According to this view, irregularity may be much more ancient than is commonly believed. Three types of argument can be used to evaluate these two hypotheses:

(1) The multiple gain hypothesis is claimed to be the most parsimonious way to explain the broad phylogenetic distribution of regularity as compared to the more sporadic occurrence of irregularity. However, this is partly a circular argument because the phylogenies it is based upon have been constructed using morphological data that includes floral symmetry and

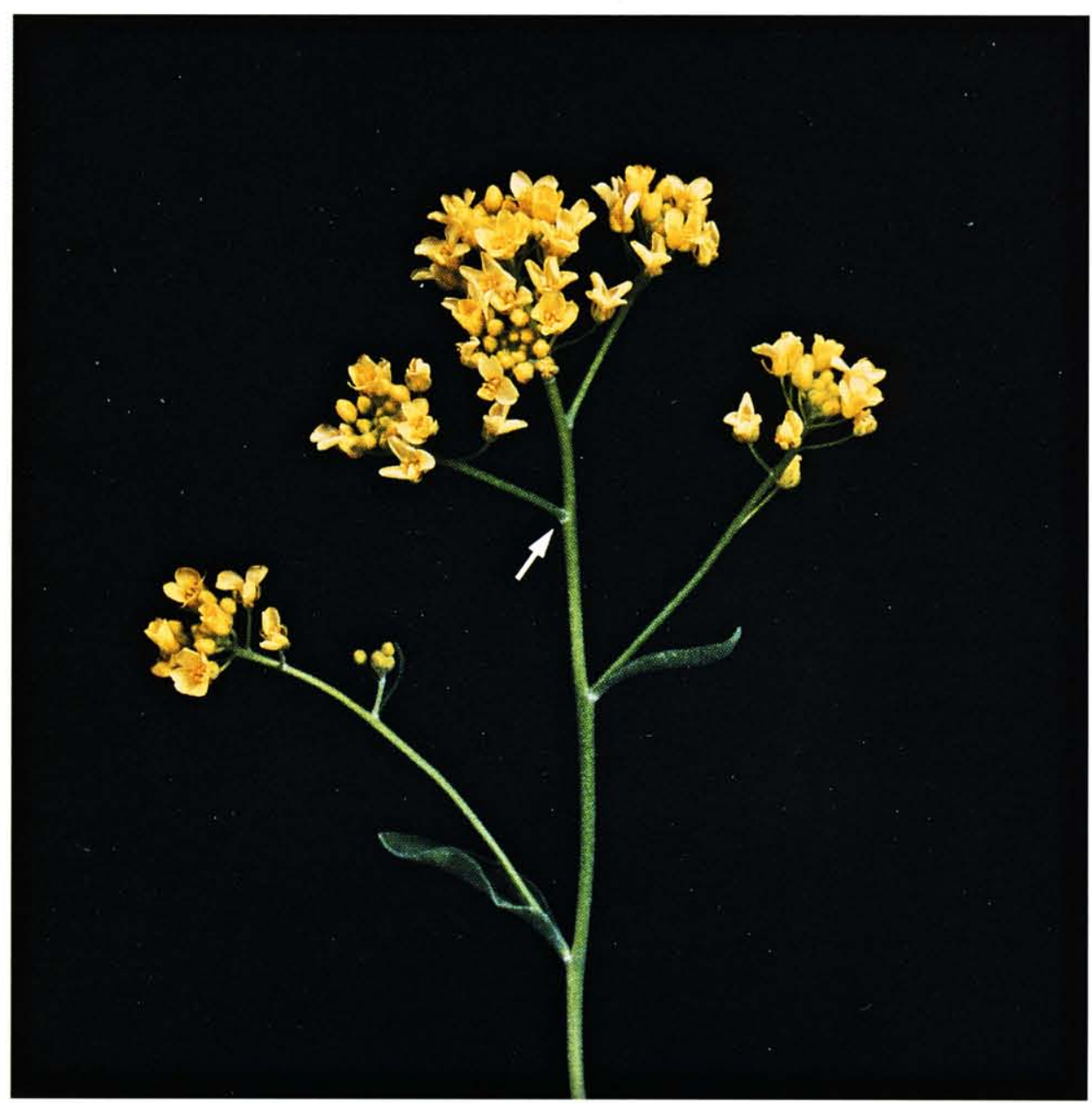

Fig. 5. Photograph of the Alyssum inflorescence. Arrow shows a secondary inflorescence not subtended by a cauline leaf. 

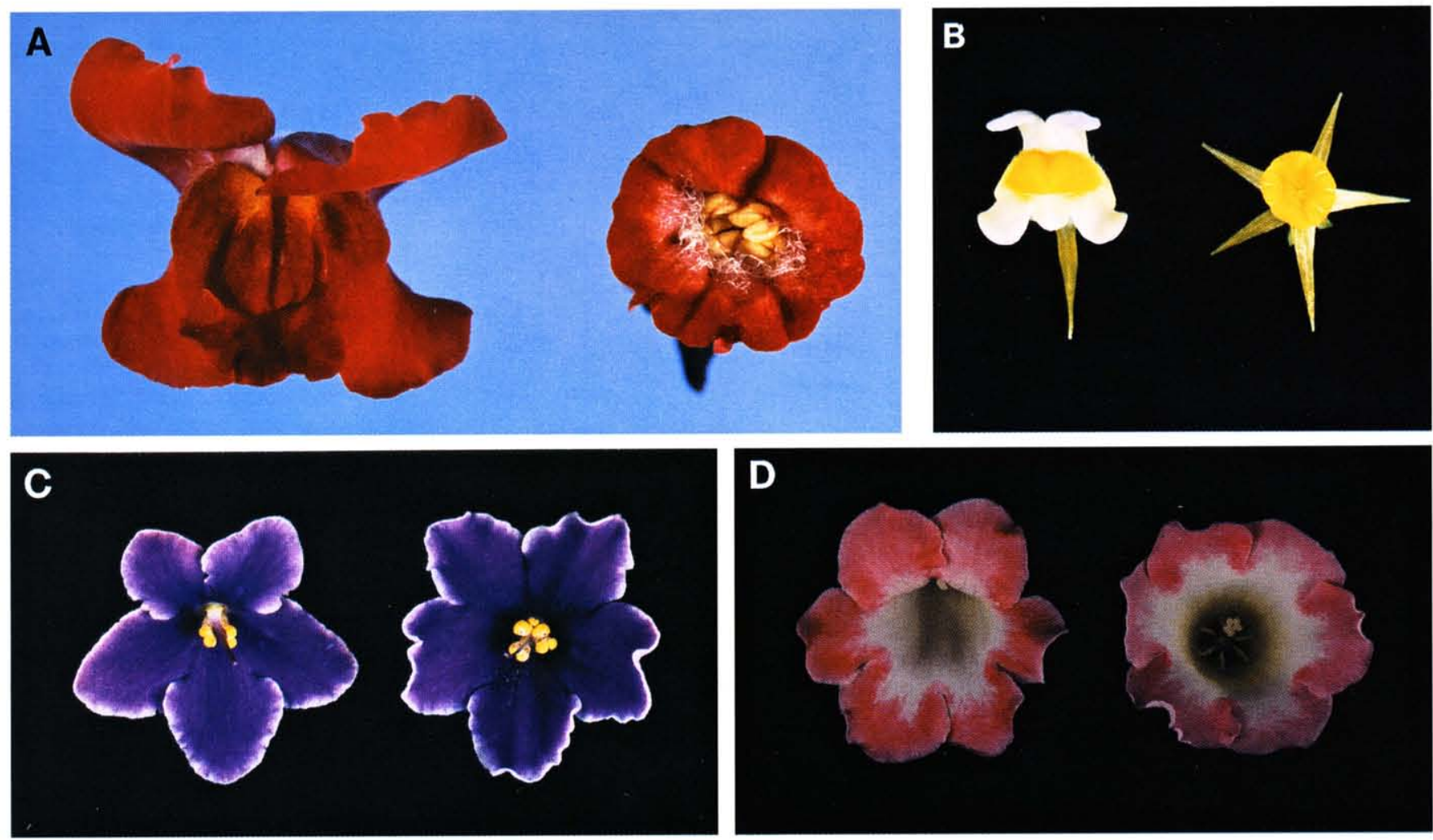

Fig. 6. Photographs of wild-type and cyc mutant of Antirrhnum (A) and comparable peloric mutants from Linaria vulgaris (B), Saintpaulia (C) and Sinningia speciosa (D). For all species, the wild type is on the left and mutant on the right.

correlated characters. An objective evaluation can only be made if the phylogenies are independent of the morphological character being assessed.

Even with a more objective phylogeny, arguments based on parsimony are problematical because they depend on knowing the relative probabilities of gaining or losing irregularity. This is illustrated in Fig. 7, which shows the relationships between families in a portion of the subclass Asteridae and is based on molecular data (Olmstead et al., 1993). A traditional view would be that the common ancestor of these species was regular, implying that irregularity evolved a minimum of 3 times independently (see (+) in Fig. 7). The alternative, is that the ancestor was irregular and implies that regularity was derived a minimum of 4 times (see (-), Fig. 7). The two explanations are about equally parsimonious, assuming that the probabilities of gaining or losing irregularity are equal. However, this is unlikely to be true because the probabilities depend on two biological variables: the genetic facility with which irregularity can be gained or lost and the adaptive consequences of the change. The cyc mutation of Antirrhinum illustrates an alteration from the irregular to the regular condition. To our knowledge, no mutations have been described in species with regular flowers that render them irregular. This would argue that it is easier to lose irregularity than to gain it. However, this must be tempered by adaptive considerations. The cyc mutation would clearly confer a selective disadvantage because bees, the primary pollinators of Antirrhinum, would be unable to enter and cross-pollinate the mutant flowers efficiently. It is therefore very difficult to establish overall whether gain or loss is the more likely explanation for the phylogeny in Fig. 7.

(2) Another argument used in favour of the multiple gain hypothesis is that irregularity is a more specialised adaptation for pollination and is therefore more likely to be derived. However, although irregularity may have originally evolved from the regular state, it need not always be the derived condition. Evolution is not a unidirectional process and specialised characters can be lost as well as gained.

(3) Irregular flowers occur in many different guises. For example, the irregular flowers of mint, pea and Antirrhinum, are all structurally very different. This has been taken as evidence in support of the multiple gain hypothesis as it seems to suggest that many independent mechanisms for generating irregularity have evolved. However, it is possible that some of the different types of irregular flowers share the same underlying mechanism for generating asymmetry. The differences may simply reflect the imposition of irregularity on different frameworks of floral development.

It is impossible to resolve these issues purely on the basis of taxonomic information. Isolating genes like $c y c$ that are involved in controlling floral symmetry allows a more direct approach to addressing these problems. The molecular basis of both the irregular and the regular condition could be addressed by comparing the activity of $c y c$-like genes in a range of species using a combination of genetic, molecular and transgenic techniques.

Mutants that give regular instead of irregular flowers, termed peloric mutants, have been described in several species in 


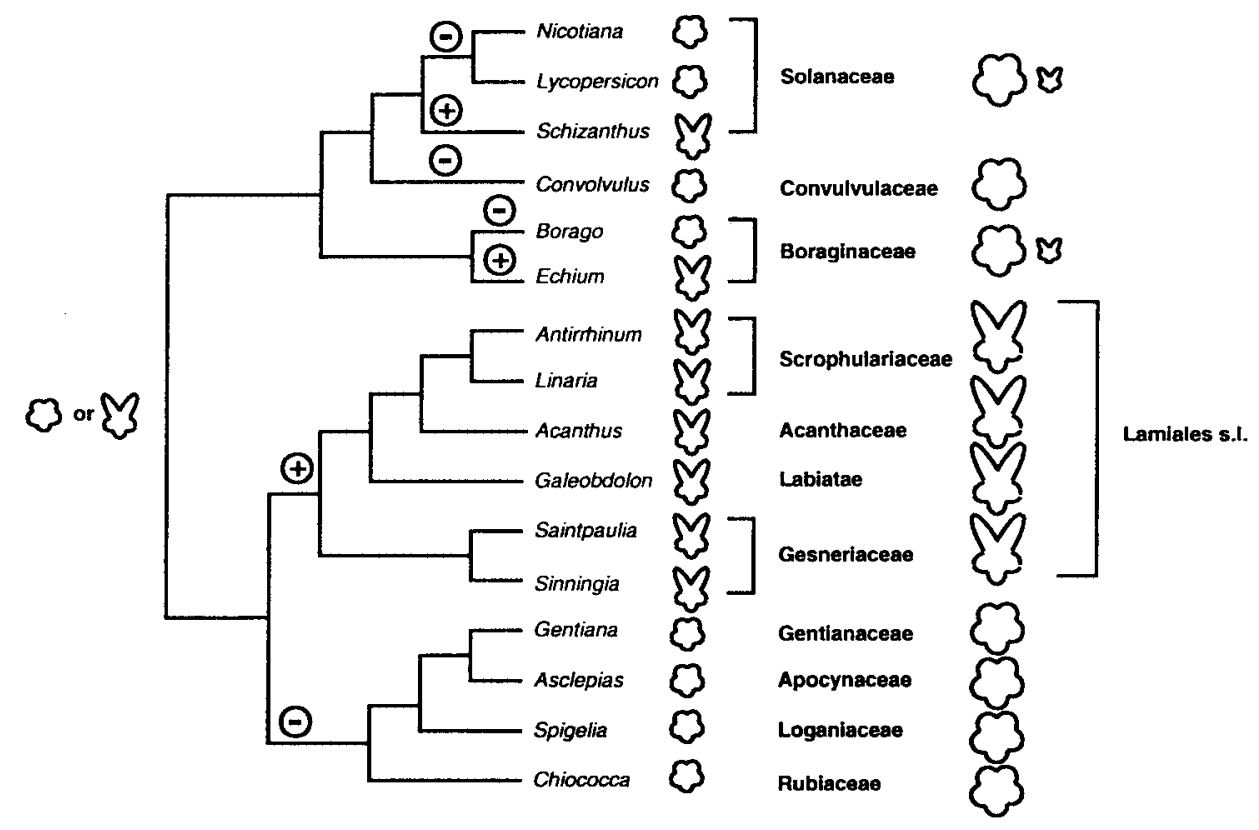

Fig. 7. Phylogenetic tree showing relationships between species and families of a portion of the subclass Asteridae. Examples of species and families having regular flowers are indicated by symmetrical symbols whereas those with irregular flowers are indicated by asymmetrical symbols. In families having a mixture of species with irregular and regular flowers, both symbols are shown, the larger symbol indicating the predominant condition within the family. If the ancestor of the group was regular, irregularity was derived independently at least 3 times in the group (indicated by + ). If the ancestor of the group was irregular, this condition was lost at least 4 times in the group (indicated by -). addition to Antirrhinum. The first peloric mutant was described by Linnaeus in Linaria vulgaris (toadflax), a close relative of Antirrhinum (Fig. 6B, Linnaeus, 1749). As with cyc, this mutant confers a ventralised phenotype, all petals resemble the lowest petal of the wild type, which is easily distinguished in Linaria by the presence of a spur. Peloric mutants with ventralised phenotypes have also been described for Saintpaulia (African violets, Fig. 6C) and Sinningia (gloxinias, Fig. 6D), both members of the family Gesneriaceae (Fig. 7). Although genetic analysis of peloric mutants has not yet been carried out in species other than Antirrhinum, it is tempting to speculate that they reflect alterations in $c y c$-like genes. This can be tested by analysing the structure and expression of $c y c$ homologues in these mutants.

All of these examples of peloric mutants are in species that are quite closely related. According to the phylogeny presented in Fig. 7 these species fall within a monophyletic group (the Lamiales s.l.; Olmstead et al., 1993) that includes only species with irregular flowers. It is likely that the common ancestor of this group had irregular flowers that depended on $c y c$-like gene activity. However, it is unclear whether irregularity in species that lie outside the Lamiales is also $c y c$-dependent. According to the multiple gain hypothesis, the mechanism for establishing irregularity might be expected to be different outside this group. The alternative hypothesis, that irregularity is more ancient, predicts that irregularity in some species outside the Lamiales should also be $c y c$-dependent. One way to distinguish between these possibilities is to determine the role of $c y c$ homologues in species with irregular flowers, such as Schizanthus (butterfly flower), Echium (Fig. 7) or even more distantly related species. If $c y c$-like genes are involved in controlling irregularity in these species, it then raises the question of whether $c y c$ was recruited once in a common ancestor of all these species or whether it was recruited independently several times. This might be resolved by studying the role, if any, of cyc-like genes in species with regular flowers and how this compares with its role in irregular species.

\section{COEVOLUTION OF INFLORESCENCE STRUCTURE AND FLORAL SYMMETRY}

There is a strong correlation between floral asymmetry and inflorescence architecture: irregular flowers are commonly associated with indeterminate racemose inflorescences whereas regular flowers can occur in both racemose and cymose inflorescences (Stebbins, 1974). This correlation may be a consequence of either selective or developmental constraints. For example, if the adaptive value of the irregular condition depends on the flowers being presented to pollinators on a racemose inflorescence, this would mean that selection was involved. Alternatively, if the genetic mechanisms for generating asymmetry are dependent on the racemose condition, a developmental constraint would be involved.

The cen mutant of Antirrhinum, which has a determinate inflorescence, provides strong evidence for developmental constraints. The cen mutant produces two types of flower: axillary flowers that are irregular and a terminal flower that is regular (Fig. 4). This appears to be a general property of cenlike mutants in a wide range of species with irregular flowers, such as Digitalis (Scrophulariaceae), Salvia grandiflora and Galeobdolon luteum (Labiatae), Delphinium elatum and Aconitum variegatum (Ranunculaceae); in all of these cases the terminal flower produced in the mutants is regular (Peyritsch, 1870,1872 ). The terminal flower of cen resembles the axillary flowers of $c y c$ mutants (Fig. 6), suggesting that $c y c$ is not active in the apical meristem. The production of $c y c$-dependent asymmetry seems to require that floral meristems are in axillary positions, and have a particular cellular environment. Axillary meristems are in an asymmetric environment, with the inflorescence apex above them and a bract below. This polarised environment could provide necessary cues for establishing the $c y c$ system. By contrast, a terminal flower meristem is in a symmetrical environment and may lack the cues required to activate $c y c$ in an asymmetrical manner. Accord- 
ingly, species producing only terminal flowers might be unable to make them irregular. However, there are apparent exceptions to this view because some species, such as Schizanthus (Fig. 7) have irregular flowers occupying terminal positions. Molecular and phenotypic analysis of these species may further our understanding of the relationship between flower position and symmetry.

Other aspects of the coevolution of inflorescence type and floral symmetry appear to reflect selective constraints. Most members of the Cruciferae have regular flowers borne on extended racemes, as shown for Arabidopsis and Alyssum (Figs 2 and 5). However, in some members of this family, such as Iberis, the inflorescence axis is shorter and produces a broad dome of flowers (corymb, Figs 1 h and 8). The overall effect of the corymb is to simulate a single large regular flower. Within the corymb flowers are irregular, the two ventral petals of each flower being much larger than the dorsal ones. This is presumably an adaptation that prevents the petals from overlapping and protruding into the centre of the inflorescence. Thus selection may have played a role in the coevolution of the compressed inflorescence axis and the irregularity of the flowers.

The coevolution of inflorescences and flowers is further illustrated by the mixed inflorescences of some of the Compositae. The inflorescence axis within this group is highly compressed to form a dense cluster of flowers (florets), termed a capitulum (Fig. 1i). In some species, such as daisy or chrysanthemum it consists of two types of florets: ray florets that are highly irregular and occupy the periphery and disc florets that are regular and occupy the central dome of the capitulum (Fig. 8). This is reminiscent of the cen phenotype of Antirrhinum, where the central terminal flower is regular and the axillary flowers are irregular. In both cases, the activation of genes controlling irregularity seems to be restricted to a peripheral zone around the inflorescence apex. In the case of a daisy, this zone gives rise only to the outermost florets whereas in Antirrhinum it produces all of the axillary flowers. Nevertheless, the production of inflorescences with a mixture of regular and irregular flowers is not found as a wild-type condition in plants with extended racemes like Antirrhinum but is common in species with a capitulum. This may reflect a selective advantage of mixed inflorescences (such as mimicking a large (bottom right). flower) when the flowers are tightly clustered within a capitulum.

The similarity between cen and daisy-like inflorescences raises the question of whether $c y c$-like genes are involved in the control of irregularity within the Compositae, a family that is quite distantly related to Antirrhinum (e.g. it lies outside the phylogeny shown in Fig. 7). It is possible to test this by looking for, and analysing the expression of, $c y c$-like genes in species from this group. This analysis may be helped by exploiting mutants described in some species of the Compositae that affect floret development. Mutants in species such as Chrysanthemum have been described that result in a capitulum comprising only irregular flowers (Fig. 8). These might be explained in terms of an extension of $c y c$-like gene activity into the central dome. Similarly, mutants that give only regular flowers might result from a loss of $c y c$-like gene activity.
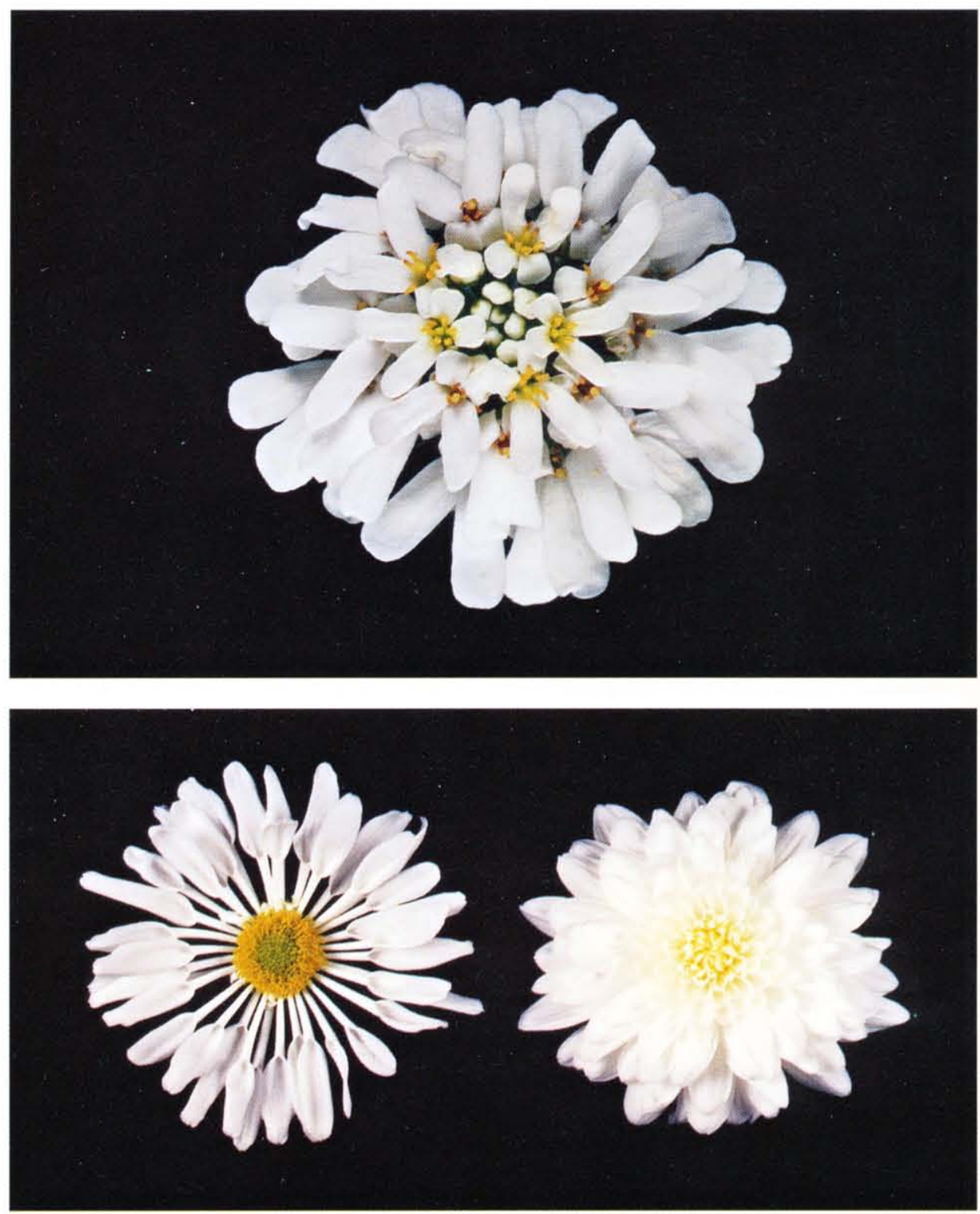

Fig. 8. Photographs of the corymb inflorescence from Iberis (top panel) and the capitulum from wild-type Chrysanthemum (bottom left) with outer irregular florets (white) and inner regular florets (yellow). A mutant Chrysanthemum, with only irregular florets is shown for comparison 
These examples illustrate the importance of studying the evolution of symmetry and inflorescence architecture together. The use of comparative molecular genetic analysis of genes such as flo, cen and cyc should start to reveal how this coevolution may have occurred.

We would like to thank Rosemary Carpenter, Desmond Bradley, Pilar Cubas and Richard Olmstead for critical comments and discussions of the manuscript and researchers at Kew Gardens for helpful discussions.

\section{REFERENCES}

Carpenter, R. and Coen, E. S. (1990). Floral homeotic mutations produced by transposon-mutagenesis in Antirrhinum majus. Genes Dev. 4, 1483-1493.

Coen, E. S., Romero, J. M., Doyle, S., Elliott, R., Murphy, G. and Carpenter, R. (1990). floricaula: a homeotic gene required for flower development in Antirrhinum majus. Cell 63, 1311-1322.
Linnaeus, C. (1749). De Peloria. Diss. Uppsala:Amoenitates Acad.

Olmstead, R. G, Bremer, B., Scott, K. M. and Palmer, J. D. (1993). A parsimony analysis of the Asteridae sensu lato based on $r b c \mathrm{~L}$ sequences. Ann. Missouri Bot. Gard. 80, 700-722.

Peyritsch, J. (1870). Uber pelorienbildungen. Sitzunger Akad. Wiss 62, 1 . 27.

Peyritsch, J. (1872). Uber Pelorienbildungen. Sitzunger Akad. Wiss 66, 135.

Schultz, E. A. and Haughn, G. W. (1991). LEAFY a homeotic gene that regulates inflorescence development in Arabidopsis. Plant Cell 3, 771-781.

Stebbins, G. L. (1974). Flowering Plants, Evolution above the Species Level. MA: Harvard University Press.

Stubbe, H. (1963). Mutanten der Kulturtomate Lycopersicon esculentum Miller IV. Die Kulturpflanze, II, 603-644.

Stubbe, H. (1966). Genetik und Zytologie von Antirrhinum L. sect. Antirrhinum Veb. Jena: Gustav Fischer.

Weberling, F. (1989). Morphology of Flowers and Inflorescences. Cambridge: Cambridge University Press.

Weigel, D., Alvarez, J., Smyth, D. R., Yanofsky, M. F. and Meyerowitz, E. M. (1992). LEAFY controls floral meristem identity in Arabidopsis. Cell 69, 843-859. 